\title{
Physician Communication Regarding Prostate Cancer Screening: Analysis of Unannounced Standardized Patient Visits
}

Bo Feng, $P b D^{1}$

Malatbi Srinivasan, $M D^{2}$

Jerome R. Hoffman, $M A, M D^{3}$

Julie A. Rainwater, $P b D^{4}$

Erin Griffin, $P b D^{4}$

Marko Dragojevic, $M A^{5}$

Frank C. Day, $M D, M P H^{6}$

Michael S. Wilkes, $M D, P b D^{7}$

${ }^{1}$ Department of Communication, University of California, Davis, Davis, California

${ }^{2}$ Department of Medicine, University of California, Davis, Davis, California

${ }^{3}$ Professor of Emergency Medicine, University of Southern California, Los Angeles, California

${ }^{4}$ Clinical and Translational Science Center, University of California, Davis, Davis, California

${ }^{5}$ Department of Communication, University of California, Santa Barbara, Santa Barbara, California

${ }^{6}$ School of Medicine, University of California, Los Angeles, Los Angeles, California

${ }^{7}$ Office of the Dean, School of Medicine, University of California, Davis, Davis, California

Conflicts of interest: autbors report none.

\section{CORRESPONDING AUTHOR}

Bo Feng, PhD

Department of Communication

1 Shields Ave

University of California

Davis, CA 95616

bfeng@ucdavis.edu

\begin{abstract}
PURPOSE Prostate cancer screening with prostate-specific antigen (PSA) is a controversial issue. The present study aimed to explore physician behaviors during an unannounced standardized patient encounter that was part of a randomized controlled trial to educate physicians using a prostate cancer screening, interactive, Web-based module.
\end{abstract}

METHODS Participants included 118 internal medicine and family medicine physicians from 5 health systems in California, in 2007-2008. Control physicians received usual education about prostate cancer screening (brochures from the Center for Disease Control and Prevention). Intervention physicians participated in the prostate cancer screening module. Within 3 months, all physicians saw unannounced standardized patients who prompted prostate cancer screening discussions in clinic. The encounter was audio-recorded, and the recordings were transcribed. Authors analyzed physician behaviors around screening: (1) engagement after prompting, (2) degree of shared decision making, and (3) final recommendations for prostate cancer screening.

RESULTS After prompting, $90 \%$ of physicians discussed prostate cancer screening. In comparison with control physicians, intervention physicians showed somewhat more shared decision making behaviors (intervention 14 items vs control 11 items, $P<.05$ ), were more likely to mention no screening as an option (intervention $63 \%$ vs control $26 \%, P<.05$ ), to encourage patients to consider different screening options (intervention $62 \%$ vs control $39 \%, P<.05$ ) and seeking input from others (intervention $25 \%$ vs control $7 \%, P<.05$ ).

CONCLUSIONS A brief Web-based interactive educational intervention can improve shared decision making, neutrality in recommendation, and reduce PSA test ordering. Engaging patients in discussion of the uses and limitations of tests with uncertain value can decrease utilization of the tests.

Ann Fam Med 2013;315-323. doi:10.1370/afm.1509.

\section{INTRODUCTION}

lthough prostate cancer is among the most common cancers among $\triangle$ men in the United States, the value of screening for prostate cancer 1 by measuring prostate-specific antigen (PSA) levels among men of average risk remains highly controversial. In many cases, PSA testing leads to invasive procedures and treatments that in turn can cause substantial harm (eg, impotence, incontinence, radiation cystitis/enteritis) ${ }^{1-3}$ Such harms may well outweigh any population-level benefit, and the US Preventive Services Task Force has now issued a recommendation against screening for average-risk men. ${ }^{4,5}$

Shared decision making is a communication process whereby clinicians collaboratively help patients understand medical information to reach valuecongruent medical decisions, especially in cases of medical uncertainty. ${ }^{6}$ In 
general, existing literature suggests that shared decision making requires that physicians engage in 3 broad groups of behaviors during consultations regarding PSA testing: (1) provision of information, ie, provision of balanced and evidence-based information regarding prostate cancer and prostate cancer screening options, including potential harms and benefits of each option;

(2) elicitation of the patient's perspective, ie, assessing a patient's wish to be actively involved in decision making, asking about his prior experience, and eliciting his concerns about prostate cancer, as well as his values and preferences regarding different screening options; and (3) guiding final decision making, ie, providing guidance without being overly directive. ${ }^{7-11}$ Even though physicians typically report that they engage in shared decision making about cancer screening, patients commonly deny having any such discussion with their physician. ${ }^{12-15}$

To understand how the physician approached discussions of risk and uncertainty around prostate cancer screening, we undertook a transcript analysis of standardized patient clinic encounters, examining (1) which elements of shared decision making occurred when physicians were prompted to discuss prostate cancer screening, (2) whether intervention physicians engaged in more behaviors related to the 3 elements of shared decision making, and (3) whether intervention physicians were more neutral than control physicians in their final recommendations for screening and ordering PSA screening tests.

\section{METHODS}

\section{Experimental Design}

This study tested the effect of an educational intervention designed to improve discussions between primary care physicians and their patients of the possible harms and benefits of prostate cancer screening. Physicians were randomized to 1 of 3 study arms, with interventions as described below. Audio recordings were made for all standardized patients' visits, which were unannounced with physicians unaware of the patient's status. Physicians provided informed consent to participate, and this study was approved by the institutional review boards of all participating institutions.

\section{Study Participants}

Primary care physicians (internal and family medicine) were recruited from 5 health systems in California. Included were university-affiliated community-based practices ( 2 sites), staff model health maintenance organizations ( 2 sites), and a private practice network (1 site). During the informed consent process, physicians agreed to complete questionnaires before and after the study and to participate in 1 unannounced, audio-recorded, standardized patient encounter in their own clinic.

\section{Interventions}

Control physicians received a brochure on prostate cancer screening that was distributed by the Centers for Disease Control and Prevention, whereas intervention physicians were exposed to an interactive, 30-minute, Web-based curriculum that included interactive roulette wheels, ${ }^{16}$ illustrative video vignettes, and other content to illustrate the potential harms, benefits, and downstream consequences of receiving prostate cancer screening, as well as methods of enhancing shared decision making. (http://edoctoring.ncl.ac.uk/ doctoring/prostate).

Intervention physicians were further divided into those who participated in the intervention (intervention $\mathrm{A}$ ), and those who participated in the intervention and had up to 3 of their regular clinic patients activated to discuss prostate cancer screening by participating in a similar patient-focused, Web-based tool immediately before a scheduled clinic visit (intervention $\mathrm{B}$ ). The patient intervention included video vignettes that depict the potential harms and benefits of undergoing prostate cancer screening.

\section{Evaluation}

Standardized patients are actors who are trained to role-play clinical scenarios in a reproducible, standardized manner. Eight actors were recruited and blinded to the research design. The standardized patients were told that this study was about differences in physician communication styles. To assure standardization, actors were trained together to portray a pleasant 62-year-old man without serious comorbidities, who recently moved to California (new to doctor), and who had a friend with recently diagnosed prostate cancer. Although study physicians were informed that they would at some point meet a standardized patient and consented accordingly, they were unaware of when the visit would occur or the identity of the standardized patient.

Each standardized patient came to clinic with a scripted distractor condition (weekend warrior shin splints) to lend authenticity to his visit. During the encounter, the patient initially focused on his shin splints, but within the first 5 minutes of the visit he was trained to prompt the physician to address prostate cancer screening by saying, "My friend back home was just diagnosed with prostate cancer. He's doing OK, but my wife was concerned and thought I should ask if I should be tested for prostate cancer." If the physician did not respond to the prompt, the standardized patient was directed to provide a second prompt. 
Toward end of the discussion, the patient again inquired about screening by asking, "What would you do if you were me?"

The standardized patients received 20 hours of directly observed training during which they practiced all aspects of their role as a patient. Throughout the study, they participated in weekly telephone calls to review their acting (via reviewing audio recordings). Unannounced visits to all physicians occurred approximately 3 months after enrollment. Intervention physicians were visited only after curricular participation. The standardized patients audio-recorded each encounter using 2 hidden microphones. Digital audio (WAV) files where transcribed to written text.

\section{Prostate Cancer Screening Abstraction Tool}

Although various measures of the extent to which health care professionals engage in shared decision making during clinical consultations exist, no existing measure fully captures the various dimensions of shared decision making conceptualized in the current project, and none of the existing measures was designed to reflect the specific topic of consultation examined in the current project (ie, consultation regarding prostate cancer screening). Using Kaplan's shared decision-making scale, ${ }_{1}^{17}$ OPTION scale, ${ }^{18}$ and items from our intervention, we developed a 32 -item transcript abstraction tool based on the 3 dimensions of shared decision making (Supplemental

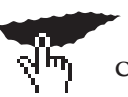
Appendix, available at http://annfammed.org/ content/11/4/315/suppl/DC1).

The provision of information dimension contained 16 items on sharing information regarding prostate cancer epidemiology (such as incidence, prevalence), screening options, treatments options, including option harms and benefits. The second dimension elicitation of patient perspectives, contained 12 items measuring the patient's interest in engaging in shared decision making, the patient's experience and perspectives of prostate cancer and prostate cancer screening, and the patient's values or preferences about different screening options. The third dimension, guiding final decision making, contained 4 items assessing the physician's guidance of the patient's final decision making, including whether the physician encouraged the patient to seek input from others or whether the physician offered to give additional information to help the patient make an informed decision. We also included 2 items (prostate cancer screening-recommendations) to assess the physician's final screening recommendations (for, against, neither) to the patient and the physician's decision to order a PSA test. All physician behaviors were coded as being observed (1) or not observed (0).

\section{Raters}

Two trained research assistants underwent approximately 20 hours of training to independently code transcripts using the qualitative software program NVivo 8 (QSR International, 2009). After training, both raters coded a random sample of 25 transcripts to assess interrater reliability. Final interrater reliability for the prostate cancer screening-shared decision-making scale was 0.84 (intraclass correlation coefficient). Interrater reliability for individual items in the prostate cancer screening-shared decision-making scale and prostate cancer screening-recommendations scale ranged from 0.6 to 1.0 (adjusted $\kappa$ ), with rater agreement ranging from $80 \%$ to $100 \%$.

\section{Baseline Measurements}

All physicians completed a preparticipation online questionnaire, which included items about demographics (age, sex, and ethnicity), their practice, and prior personal and professional experience with prostate cancer, attitudes, and self-described, shared decisionmaking behaviors. Poststudy questionnaires were completed by both physicians and actual patients.

\section{Analysis}

To assess the impact of actual intervention participation on physician behaviors, we performed an as-treated analysis, comparing the behaviors of physicians who participated and those who did not participate in the intervention. Given that the focus of this article is on assessing the effectiveness of the intervention on physician behavior, we combined the 2 intervention groups in the final analysis. Accordingly, we report all results in terms of 2 groups-intervention and control.

We undertook generalized linear mixed modeling (GLM) for our major outcomes of shared decision making, final prostate cancer screening recommendations, and physician statement of PSA test ordering. We created an overall shared decision-making score (sum of all 32 coded shared decision-making items) and subscale for each domain (information provision, perspective elicitation, final decision guidance), weighting each item equally. A multilevel modeling approach (GLM) was used to simultaneously estimate the intervention effects while controlling for the hierarchical nature of our data and explainable within-clinic correlations and design effects resulting from the stratified cluster-randomized design. We adjusted for health care network, physician site, physician age, sex, ethnicity, and where appropriate, physician preparticipation knowledge about prostate cancer and prostate cancer screening. All analyses were conducted with SAS 9.2 (SAS Institute). 
Figure 1. Randomization scheme and participation flow of an intervention to improve shared decision making during prostate cancer screening discussions by primary care physicians, as-treated transcript analysis.

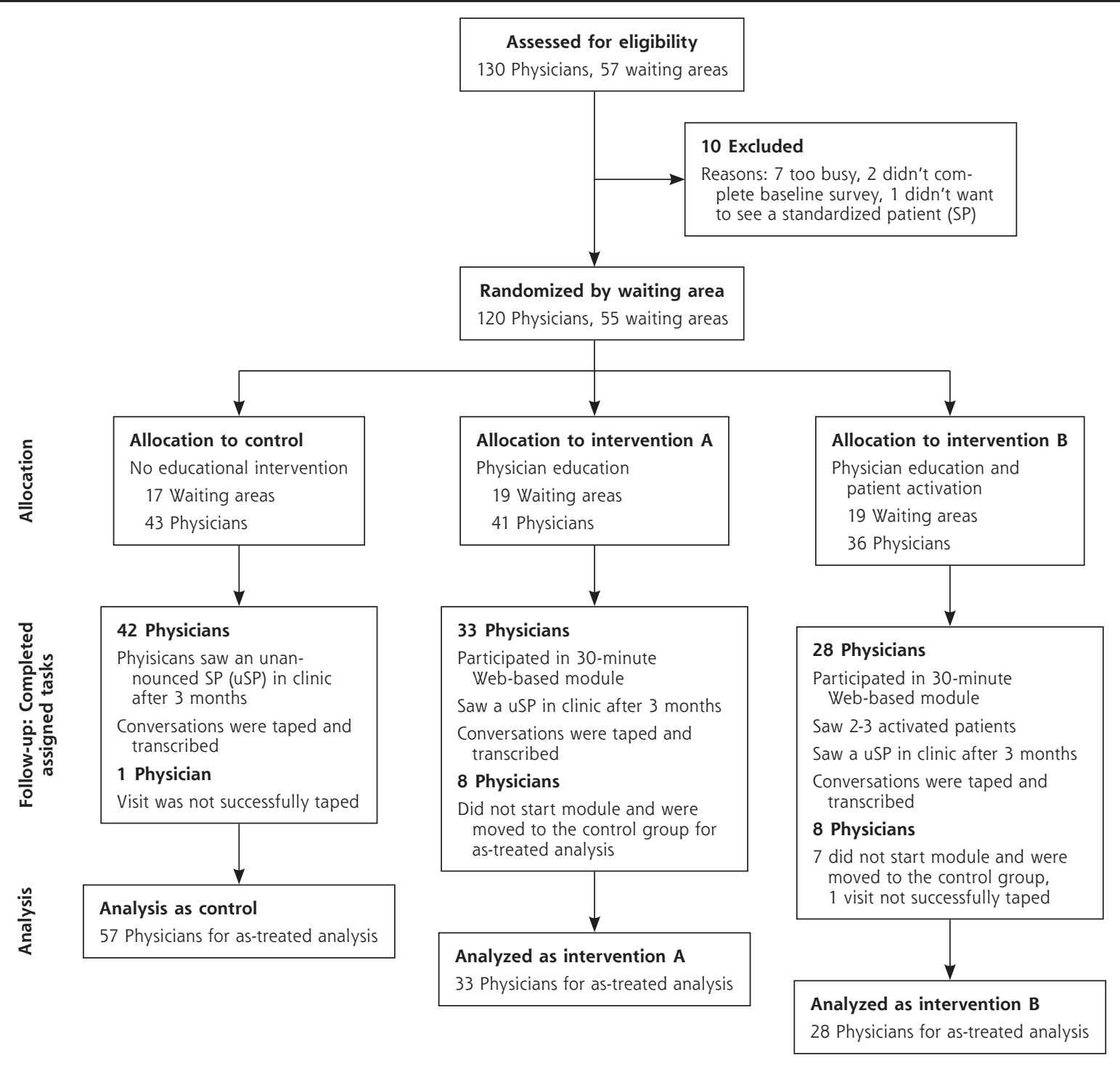

\section{RESULTS}

\section{Physician Characteristics}

Figure 1 summarizes study recruitment, enrollment, and participant allocation. Physicians were $68 \%$ male, aged an average of 43 years, and had been practicing at their clinic sites for about 8 years. On prestudy questionnaires, physicians in both study groups self-reported high rates of engaging in shared decision making, including that, all or most of the time, they took their patient's preferences into account when making treatment decisions (92\%), offered their patients choices in their medical care (91\%), discussed the pros and cons of each choice (78\%), and asked their patients to state which choice or option they would prefer $(79 \%)$. Postvisit detection rate of the standardized patients by physicians was less than $10 \%$.

Of the 118 study physicians whose visits were audio-recorded, 15 intervention physicians did not complete the education intervention, and were treated as controls. Based on transcript analysis, the shared decision-making results in the 2 intervention groups are largely similar (Supplemental Table 1, available online at http://annfammed.org/content/11/4/315/ suppl/DC1). The subscale data for the multilevel modeling approach (GLM) used to estimate the inf intervention effects are shown in Supplemental Tables 
2 through 5, available online at http://annfammed. org/content/11/4/315/suppl/DC1).

\section{Physician Engagement in Shared Decision Making Information Provision \\ About one-half of physicians discussed with the stan- dardized patient the epidemiology of prostate cancer and prostate cancer screening, such as individual risk factors for prostate cancer, natural history of prostate cancer, or symptoms (Table 1 ).}

[Prevalence] First of all, prostate cancer is exceedingly common. By the time you're 80 years old, you will probably have some low-grade prostate cancer going on.

[Natural history] A lot of men die with prostate cancer, but it has nothing to do with what kills them.

[Mortality] It turns out that many prostate cancers are not life limiting, and the younger you are, the more worrisome it could be in terms of life limitation. ...but many prostate.. most prostate cancers are not life limiting. ... but there are a percentage that are [standardized patient: Um-hmmm] life ending and life limiting.

About $90 \%$ of physicians made a statement acknowledging that the accuracy of prostate cancer screening is imperfect. A greater percentage of intervention physicians discussed other possible drawbacks associated with PSA testing (intervention $80 \%$ vs control $60 \%, P<.05)$ and mentioned watchful waiting or no screening as an alternative (intervention $63 \%$ vs control 26\%, $P<.05)$.

[PSA accuracy] The PSA test is the real issue, because that's how a lot of men get screened for prostate cancer, and it's really inaccurate.

[Watchful waiting/no screening, advantages] There are some men who watch their prostate cancer grow for 20 or 30 years. I mean-I have a man who's been watching it since he was 60 , and he's now 80 something. It tends to be a very slow-growing cancer.

[Watchful waiting/no screening, disadvantages] If we'd never checked for PSA, many patients would have led their full life without even knowing there was a problem. Yet, if we don't do these tests, we're more likely to miss a serious prostate cancer.

A relatively large percentage of physicians in each study arm provided information about the steps that would be taken subsequent to abnormal PSA test results (intervention $85 \%$, control $70 \%$ ).

[Next steps after an abnormal PSA test] Worst case scenariois you get a PSA, and it's a little bit elevated, we ultimately end up sorting it out and say, "Well, let's do a biopsy because we think it's prostate cancer." We recommend different things, and you might have surgery or radiation, and then you have a complication, like impotence or incontinence or something else. No one tells you that you could have lived the rest of your life perfectly well and died of something different. But now, because we did something, you can have a complication, like impotence or incontinence, that stays with you for the next 25 years."

\section{Elicitation of Patient \\ Perspectives}

Overall, about one-half of the physicians asked the standardized patient about their medical history, family history, and direct experiences with prostate cancer and prostate cancer screening (Table 2). The great majority of physicians in all 3 groups did not explicitly involve patients in shared decision making around prostate cancer screening. Only $7 \%$ of physicians asked about the patient's specific concerns about prostate cancer, $3 \%$ attempted to identify what the patient already knew about PSA testing and prostate cancer, and $3 \%$ solicited 
patient's concerns about having side effects from a test or treatment of prostate cancer.

[Concerns about prostate cancer] I know you were asking about prostate. Are you worried that you may have prostate cancer?

[Concerns about side effects] You need to think about-you have to decide-you know, what worries you more? Are you more worried about side effects of treatment, or are you worried about death from prostate cancer given the risk is so low. You have to decide what you're willing to live with or not.

After provision of information, only $25 \%$ asked whether the standardized patient understood the

\section{Table 2. Primary Care Physician Behaviors in Eliciting Patients' Perspectives About Prostate Cancer or Prostate Cancer Screening: 12 Coded Items}

\begin{tabular}{|c|c|c|c|}
\hline Elicitation of Patient Perspectives & $\begin{array}{c}\text { Overall } \\
(\mathrm{N}=118) \%\end{array}$ & $\begin{array}{c}\text { Control } \\
(n=57) \%\end{array}$ & $\begin{array}{l}\text { Intervention } \\
(n=61) \%\end{array}$ \\
\hline $\begin{array}{l}\text { Asks about patient's direct previous } \\
\text { experience }\end{array}$ & 46 & 53 & 40 \\
\hline Ask about patient's family history & 47 & 40 & 54 \\
\hline $\begin{array}{l}\text { Asks about patient's indirect personal } \\
\text { experience }{ }^{\mathrm{a}}\end{array}$ & 8 & 2 & 15 \\
\hline Asks about patient's knowledge & 3 & 0 & 5 \\
\hline $\begin{array}{l}\text { Asks about patient's concerns about hav- } \\
\text { ing PCA }\end{array}$ & 7 & 2 & 12 \\
\hline $\begin{array}{l}\text { Solicits concerns about having side effects } \\
\text { from test or treatment }{ }^{a}\end{array}$ & 3 & 0 & 7 \\
\hline Offers opportunities to ask questions & 13 & 12 & 13 \\
\hline $\begin{array}{l}\text { Checks patient's understanding of } \\
\text { information }\end{array}$ & 25 & 19 & 30 \\
\hline $\begin{array}{l}\text { Explains why shared decision making is } \\
\text { necessary for PCS }\end{array}$ & 28 & 21 & 34 \\
\hline $\begin{array}{l}\text { Elicits patient's preferred level of involve- } \\
\text { ment in decisions }\end{array}$ & 0 & 0 & 0 \\
\hline $\begin{array}{l}\text { Assesses patient's preferences for receipt } \\
\text { of information }\end{array}$ & 0 & 0 & 0 \\
\hline Asks patient his decision & 34 & 28 & 39 \\
\hline
\end{tabular}

PCS = prostate cancer screening; PSA = prostate-specific antigen.

Note: Percentage of physicians who inquired about their patient's perspective about prostate cancer or prostate cancer screening at least once during an unannounced standardized patient visit.

a $P<.05$.

Table 3. Primary Care Physicians Behaviors in Guiding Patient in Final Decision Making Around Prostate Cancer Screening: 4 Coded Items

\begin{tabular}{|c|c|c|c|}
\hline Guiding Final Decision & $\begin{array}{l}\text { Overall } \\
(\mathrm{N}=118) \%\end{array}$ & $\begin{array}{l}\text { Control } \\
(n=57) \%\end{array}$ & $\begin{array}{l}\text { Intervention } \\
(n=61) \%\end{array}$ \\
\hline $\begin{array}{l}\text { Indicates that decisions should be based } \\
\text { on patient's values }\end{array}$ & 19 & 11 & 28 \\
\hline Tells patient to think about options ${ }^{a}$ & 51 & 39 & 62 \\
\hline $\begin{array}{l}\text { Encourages patient to seek input from } \\
\text { others }^{\text {a }}\end{array}$ & 16 & 7 & 25 \\
\hline Offers to provide additional information ${ }^{a}$ & 27 & 18 & 36 \\
\hline \multicolumn{4}{|c|}{$\begin{array}{l}\text { Note: Percentage of physicians who provided guidance for final decision making regarding prostate cancer } \\
\text { screening, at least once during an unannounced standardized patient visit. }\end{array}$} \\
\hline
\end{tabular}

information discussed, and $13 \%$ asked whether the patient had any questions. No physician inquired as to how involved the patient wished to be in medical

Guiding Final Decision Making

Overall, a relatively small percentage of physicians in each group engaged in behaviors that would facilitate the patient's final decision making about prostate cancer screening (Table 3 ). Across the 3 groups, only of physicians stated that the final decision about screening should be based on the patient's values and preferences, and $27 \%$ offered to provide additional information regarding screening or PSA testing, if needed.

[Choice based on patient values] But, basically, long story short, it's up to you. Some men really want to know if they have a cancer-whether or not it is serious. Other men don't really care. And it's really your choice.

[Provision of written material or resources] It depends on your kind of level of concern and worry. Most people do them [PSA tests] and are comfortable with the results, and we manage it and it's fine. We may be impacting lives by reducing the- the illness burden of prostate cancer.

Although the overall percentages of shared decision making remained low, intervention physicians provided more neutral guidance. For example, compared with control physicians, more intervention physicians asked the patient to consider the different options before making a decision about screening (intervention $62 \%$ vs control $39 \%, P<.05)$ or encouraged the patient to seek input from others (intervention $25 \%$ vs control $7 \%, P<.05)$.

[Patient to consider options before decision] So there are reasons to screen and reasons not to screen. It all boils down to your values and preferences around the benefits of maybe picking up a cancer early vs the high risks of side effects and the chance that the test will tell you that you have a prostate cancer that will lead you to do something to treat 
Table 4. Summary of Primary Care Physician Behaviors in Shared Decision Making Regarding Prostate Cancer or Prostate Cancer Screening

\begin{tabular}{|c|c|c|c|c|}
\hline Behavior & Range & $\begin{array}{c}\text { Overall } \\
(N=118) \\
\text { Mean No. }\end{array}$ & $\begin{array}{c}\text { Control } \\
(n=57) \\
\text { Mean No. }\end{array}$ & $\begin{array}{c}\text { Intervention } \\
(n=61) \\
\text { Mean No. }\end{array}$ \\
\hline $\begin{array}{l}\text { Overall shared decision making- } \\
\text { PCS score }{ }^{a}\end{array}$ & $0-32$ & 12.2 & 10.7 & 13.5 \\
\hline Provision of information scale & $0-16$ & 8.9 & 8.2 & 9.5 \\
\hline $\begin{array}{l}\text { Elicitation of patient's perspectives } \\
\text { scale }\end{array}$ & $0-12$ & 2.1 & 1.8 & 2.5 \\
\hline Guiding decision-making scale ${ }^{a}$ & $0-4$ & 1.1 & 0.7 & 1.5 \\
\hline \multicolumn{5}{|l|}{ PCS = prostate cancer screening. } \\
\hline \multicolumn{5}{|c|}{ Note: Each item in the scale was given a value of $0=$ did not occur, or $1=$ occurred. } \\
\hline
\end{tabular}

recent recommendation against screening by the US Public Service Task Force, ${ }^{5}$ interventions such as this one may be important adjuvants to help influence physicians' behaviors regarding controversial medical topics with public health implications.

Our transcript analysis found that whereas some behaviors were similar between physician groups, intervention physicians showed a greater number of patient-centered behaviors, asked about or provided more informa-

that cancer when in fact you have a slow growing cancerreally just a collection of abnormal cells - that will never effect your life.

[Seek input from others] So, your homework will be thinking about prostate cancer screening and discussing it with your wife.

Overall and Subscales of Shared Decision Making Table 4 summarizes the physicians' overall engagement in shared decision making, as well as each of the 3 domains. On average, of the 32 behavioral elements identified in our scale, intervention physicians addressed a greater number of shared decision-making elements than control physicians (score: 13.5 vs 10.7, $P<.05$ ). For each domain, intervention physicians appeared to show small improvement in comparison with control.

\section{Prostate Cancer Screening Recommendations} When asked by the standardized patient regarding prostate cancer screening, "Would you get this test if you were me?" most physicians (75\%) offered an opinion (Table 5). Intervention physicians, however, were less likely to state that they would order a PSA test for the standardized patient (intervention $31 \%$ vs control $60 \%, P<.01)$. tion about prostate cancer screening, and involved standardized patients more frequently in those discussions. Because each physician had only 1 encounter with a standardized patient, our transcript study was not powered to detect small differences in individual behavioral items. Still, our descriptive analyses generated strong evidence suggesting that a brief educalead to objectively measured behavioral changes in primary care practice rather than merely a change in reported behavior, attitudes, or knowledge. Our intervention seemed particularly effective in prompting physicians to mention no screening or watchful waiting as an alternative to prostate cancer screening, to encourage patients to consider different options, and to seek input from others. Although other educational opportunities (such as small-group meetings or discussions with experts) have been considered ideal for teaching communication skills, it seems that a more limited but easily accessible intervention, such as our Web-based educational intervention, has the benefit of being time effective and less resource intensive. ${ }^{19}$

It should be noted that the intervention produced only a modest change in the physicians' observed overall level of engagement in shared decision making about prostate cancer screening. One possible explanational intervention focused on physician behavior can

\section{DISCUSSION}

By analyzing standardized patient transcripts of the actual conversations between physicians and patients, this study offers unique and important insights into how physicians actually behaved when prompted to discuss the risk and uncertainty of prostate cancer screening, and the positive effect a brief intervention tool can have on promoting physicians' clinical practice. In light of the
Table 5. Summary of Physician Final Clinical Recommendations After Prompting by Unannounced Standardized Patient

\begin{tabular}{lccc}
\hline Recommendation & $\begin{array}{c}\text { Overall } \\
(\mathbf{N}=\mathbf{1 1 8})\end{array}$ & $\begin{array}{c}\text { Control } \\
(\mathbf{n}=\mathbf{5 7})\end{array}$ & $\begin{array}{c}\text { Intervention } \\
(\mathbf{n}=\mathbf{6 1})\end{array}$ \\
\hline Recommended in favor of PCS & 59 & 68 & 49 \\
Recommended against PCS & 16 & 11 & 21 \\
$\begin{array}{l}\text { Made no recommendation } \\
\begin{array}{l}\text { Physician stated that he or she } \\
\text { would order a PSA blood test }\end{array}\end{array}$ & 25 & 21 & 30 \\
\hline PCS $=$ prostate cancer screening; PSA $=$ prostate-specific antigen. & & 31 \\
a $P<.01$. & 60 & \\
\hline
\end{tabular}


tion is that the physicians' engagement in shared decision making during clinical counseling is likely to be not only a function of the physicians' attitudes toward and knowledge of shared decision making and the specific medical issue under discussion, but also a function of other factors, such as the physicians' individual style of communication and time constraints. ${ }^{20}$ Another possibility is that because our standardized patient encounters occurred up to 3 months after the 30 -minute intervention, the impact of the intervention may have attenuated over time without reinforcement.

At the same time, our study showed that physicians in all groups performed poorly in many aspects of counseling regarding prostate cancer screening and in shared decision making. In particular, similar to what has been found in previous studies, ${ }^{8,13-15}$ we found that there was a significant lack of effort to elicit patients' perspectives (knowledge, concerns, values, preferences), which is a critical component of shared decision making. ${ }^{9-11}$ Given that more than $90 \%$ of physician participants self-reported that they usually took their patients' preferences into account when making treatment decisions (compared with only about $20 \%$ who explicitly told the standardized patient that decisions should be based on the patient's values and preferences), there may be a large gap between (1) the physicians' perception of or belief in their communication skill and their actual communication behavior, and (2) between the physicians' assumption of their patients' perspectives and their patients' actual perspectives.

Our study has several limitations. First, our transcript analysis codified physician behaviors as dichotomous-displayed or not displayed. Thus, although weighting more items covered as better quality, our analysis would not credit those physicians who spent considerable time clarifying a single topic or question more thoroughly. Not all aspects of shared decision making may be equally important, and standard counseling provided by these physicians may have been quite appropriate for their actual patients.

Second, clinical encounters, similar to other social interactions, are complex, dynamic, and involve contributions from all parties. Physicians likely make counseling decisions based on subtle behavioral cues provided by their patients and their personal history with the individual. Although our standardized patients adhered to the study protocol, subtle behavioral variations may have influenced counseling behaviors.

Third, our transcript analyses focused exclusively on the physicians' verbal behaviors. Nonverbal behaviors play an important role in social interactions and might have had an impact on the dynamics and outcomes of the interaction. ${ }^{21}$ Empirical studies of physicians' nonverbal behaviors during clinical consultations have been relatively scarce, ${ }^{22,23}$ but there is evidence that affiliation-showing nonverbal behaviors, such as head nodding, eye contact, and smiling, are positively associated with various consultation outcomes, including patient satisfaction and understanding, ${ }^{24-26}$ physical functioning, ${ }^{27}$ and quality of diagnosis. ${ }^{28}$

Fourth, we were coding only clear statements, and implied or ambiguous statements that were not clear were not coded as having occurred. As a result, behaviors that would be recognized with nonverbal or cumulative cues-for instance, a general sense of recommendations for prostate cancer screening being neutral, or positively or negatively biased, would have in our study been underrecognized.

Finally, given that the standardized patients visited the physicians as new patients, and each physician saw only one standardized patient, there might be a firstvisit bias in the assessment of a physician's engagement in shared decision making. ${ }^{29}$ More specifically, because the topic of prostate cancer screening was brought up by the standardized patient as a side issue that did not require immediate intervention, many physicians might prefer to engage the patient in decision making about the issue over a series of patient visits. If first-visit bias existed in this study, there might be a major underestimation of the physicians' competence in shared decision making.

In summary, this study suggests that a relatively brief educational intervention can result in behavior change both with regard to shared decision making and perhaps even in test ordering. As consumers are bombarded with direct-to-consumer advertising of clinical tests and drugs, there is a potential growing demand for more care. This study shows, however, that when clinicians and patients engage in meaningful discussions around the uses and limitations of at least one technology (PSA tests), utilization of that technology may decrease, potentially decreasing the utilization of other tests with uncertain value.

To read or post commentaries in response to this article, see it online at http://www.annfammed.org/content/11/4/315.

Key words: prostate cancer; prostate cancer screening; primary care; shared decision making; unannounced standardized patients; qualitative analysis; medical education; randomized controlled trial; health communication; risk-benefit assessment; patient-centered care

Submitted March 2, 2012; submitted, revised, September 18, 2012; accepted October 19, 2012.

Funding support: This work was supported by the Centers for Disease Control and Prevention grant R01PH000019.

Clinical Trial Registration: Shared Decision Making: Prostate Cancer Screening, NCT 00207649, http://clinicaltrials.gov/ct2/results?term = NCT+ 00207649 . 
Acknowledgments: We would like to acknowledge the work of research associate Richard Maranon (UCLA) in coding the transcripts. Our standardized patients (1-8) worked hard to maintain role fidelity and make/ keep appointments in 5 different health systems. Thanks also go to Stacy Hiyashi, Chris Harlan, and Jerilyn Higa for their managerial expertise.

\section{References}

1. Andriole GL, Crawford ED, Grubb RL III, et al; PLCO Project Team. Mortality results from a randomized prostate-cancer screening trial. N Engl J Med. 2009;360(13):1310-1319.

2. Schröder FH, Hugosson J, Roobol MJ, et al; ERSPC Investigators. Screening and prostate-cancer mortality in a randomized European study. N Engl J Med. 2009;360(13):1320-1328.

3. Volk RJ, Cass AR, Spann SJ. A randomized controlled trial of shared decision making for prostate cancer screening. Arch Fam Med. 1999; 8(4):333-340.

4. Chou R, Croswell JM, Dana T, et al. Screening for prostate cancer: a review of the evidence for the U.S. Preventive Services Task Force. Ann Intern Med. 2011;155(11):762-771.

5. Moyer VA; U.S. Preventive Services Task Force. Screening for prostate cancer: U.S. Preventive Services Task Force recommendation statement. Ann Intern Med. 2012;157(2):120-134.

6. Hoffman RM, Helitzer DL. Moving towards shared decision making in prostate cancer screening. J Gen Intern Med. 2007;22(7):1056-1057.

7. Braddock CH III, Edwards KA, Hasenberg NM, Laidley TL, Levinson W. Informed decision making in outpatient practice: time to get back to basics. JAMA. 1999;282(24):2313-2320.

8. Katz ML, Broder-Oldach B, Fisher JL, et al. Patient-provider discussions about colorectal cancer screening: who initiates elements of informed decision making? J Gen Intern Med. 2012;27(9):1135-1141.

9. Elwyn G, Frosch D, Thomson R, et al. Shared decision making: a model for clinical practice. J Gen Int 2012; May 23 online.

10. Makoul G, Clayman ML. An integrative model of shared decision making in medical encounters. Patient Educ Couns. 2006;60(3): 301-312.

11. White MK, Keller V, Horrigan LA. Beyond informed consent: The shared decision making process. J Clin Outcomes Manag. 2003;10(6): 323-328.

12. Chan EC, Vernon SW, Ahn C, Greisinger A. Do men know that they have had a prostate-specific antigen test? Accuracy of self-reports of testing at 2 sites. Am J Public Health. 2004;94(8):1336-1338.

13. Dunn AS, Shridharani KV, Lou W, Bernstein J, Horowitz CR. Physician-patient discussions of controversial cancer screening tests. Am J Prev Med. 2001;20(2):130-134.

14. Federman DG, Goyal S, Kamina A, Peduzzi P, Concato J. Informed consent for PSA screening: does it happen? Eff Clin Pract. 1999;2(4): 152-157.
15. Guerra CE, Jacobs SE, Holmes JH, Shea JA. Are physicians discussing prostate cancer screening with their patients and why or why not? A pilot study. J Gen Intern Med. 2007;22(7):901-907.

16. Hoffman JR, Wilkes MS, Day FC, Bell DS, Higa JK. The roulette wheel: an aid to informed decision making. PLoS Med. 2006;3(6): e137-e142.

17. Heisler M, Bouknight RR, Hayward RA, Smith DM, Kerr EA. The relative importance of physician communication, participatory decision making, and patient understanding in diabetes self-management. J Gen Intern Med. 2002;17(4):243-252.

18. Elwyn G, Edwards A, Wensing M, Hood K, Atwell C, Grol R. Shared decision making: developing the OPTION scale for measuring patient involvement. Qual Saf Health Care. 2003;12(2):93-99.

19. Frosch DL, Kaplan RM, Felitti VJ. A randomized controlled trial comparing internet and video to facilitate patient education for men considering the prostate specific antigen test. J Gen Intern Med. 2003;18(10):781-787.

20. Gravel K, Légaré F, Graham ID. Barriers and facilitators to implementing shared decision-making in clinical practice: a systematic review of health professionals' perceptions. Implement Sci. 2006;1:16.

21. Beck RS, Daughtridge R, Sloane PD. Physician-patient communication in the primary care office: a systematic review. J Am Board Fam Pract. 2002;15(1):25-38.

22. Mast MS. On the importance of nonverbal communication in the physician-patient interaction. Patient Educ Couns. 2007;67(3):315-318.

23. Finset A, Piccolo LD. Nonverbal communication in clinical contexts. In: Rimondini M, ed. Communication in Cognitive Behavioral Therapy. 1st ed. New York: Springer, 2010: 107-128.

24. Larsen KM, Smith CK. Assessment of nonverbal communication in the patient-physician interview. J Fam Pract. 1981;12(3):481-488.

25. Hall JA, Harrigan JA, Rosenthal R. Nonverbal behavior in clinician patient interaction. Appl Prev Psychol. 1995;4:21-37.

26. Griffith CH III, Wilson JF, Langer S, Haist SA. House staff nonverbal communication skills and standardized patient satisfaction. J Gen Intern Med. 2003;18(3):170-174.

27. Ambady N, Koo J, Rosenthal R, Winograd CH. Physical therapists' nonverbal communication predicts geriatric patients' health outcomes. Psychol Aging. 2002;17(3):443-452.

28. Bensing JM, Kerssens JJ, van der Pasch M. Patient-directed gaze as a tool for discovering and handling psychosocial problems in general practice. J Nonverbal Behav. 2005;19:223-242.

29. Tamblyn RM, Abrahamowicz M, Berkson L, et al. First-visit bias in the measurement of clinical competence with standardized patients. Acad Med. 1992;67(10)(Suppl):S22-S24. 